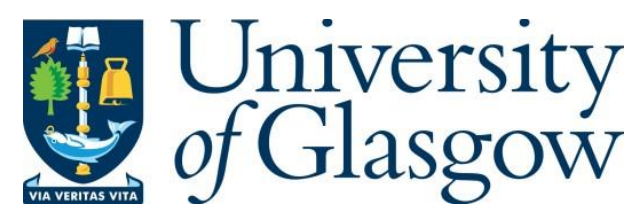

Kent, A., Berry, D. M., Budds, K., Skipper, Y. and Williams, H. L. (2017) Promoting writing amongst peers: establishing a community of writing practice for early career academics. Higher Education Research and Development, 36(6), pp. 1194-1207.

There may be differences between this version and the published version. You are advised to consult the publisher's version if you wish to cite from it.

http://eprints.gla.ac.uk/185741/

Deposited on: 2 May 2019

Enlighten - Research publications by members of the University of Glasgow http://eprints.gla.ac.uk 


\author{
Promoting Writing Amongst Peers: \\ Establishing a Community of Writing Practice for Early Career Academics
}

\begin{abstract}
Author affiliations:
Alexandra Kent: a.kent@ keele.ac.uk, +44 (0)1782 733289 - corresponding author

Donna M. Berry, d.m.berry@keele.ac.uk, +44 (0)1782 733391

Kirsty Budds, k.budds@ keele.ac.uk, +44 (0)1782 734265

Yvonne Skipper, y.skipper@keele.ac.uk, +44 (0)1782 733385

Helen L. Williams, h.1.williams@keele.ac.uk, +44 (0)1782 733664
\end{abstract}

\author{
School of Psychology, \\ Dorothy Hodgkin Building, \\ Keele University, \\ Keele, ST5 5BG \\ UK
}

Published as:

Kent, A., Berry, D., Budds, K., Skipper, Y., Williams, H. (2017) Promoting writing amongst peers: establishing a community of writing practice for early career academics, Higher Education Research \& Development (online access) 
Promoting Writing Amongst Peers:

Establishing a Community of Writing Practice for Early Career Academics

Alexandra Kent, Donna M. Berry, Kirsty Budds, Yvonne Skipper, and Helen L. Williams School of Psychology, Keele University

\begin{abstract}
In the current research-focused climate, academics are facing increasing pressure to produce research outputs. This pressure can prove particularly daunting for early career (EC) academics, who are simultaneously attempting to master new teaching and administrative demands while establishing their own independent research trajectories. Previous reports suggest that academic writing retreats can be an effective way of increasing research outputs. Such retreats generally involve academics from a range of career stages and require expert facilitators. Through organising a series of structured writing events, this project aims to cultivate an enduring community of practice for academic writers. Reflecting on our EC retreat and subsequent writing days with academics from different career stages, we suggest that success hinged on three key factors: 1. A formal structure comprising bounded periods of intense writing, flanked by group reviewing and goal-setting; 2 . Co-located writing with participants based in a shared space, away from their usual workstation and distractions; 3. Peer discussions involving participants at a similar career stage. Specifically we found that writing amongst 'equals' increased productivity and confidence amongst EC academics.
\end{abstract}

Keywords: Writing retreats, Early career academics, Communities of practice, Academic writing Word count: 6,982 words 


\author{
Promoting Writing Amongst Peers: \\ Establishing a Community of Writing Practice for Early Career Academics
}

Academics face continual pressure to publish as a key focus of university research strategies. Murray and Newton (2009) note that barriers for academic writing include course administration, teaching and meeting with students, and other non-academic activities - all of which compete for the attention of academics. However, much of the existing literature on academic writing focuses on advice or techniques, rather than the associated barriers to writing, such as motivation, time pressures and experience (Moore 2003). Research suggests that academics who are more successful at writing are not necessarily less busy, but find it easier to set aside other tasks and focus on writing (Mayrath 2008). Thus, whilst academic writing is difficult for many (Grant and Knowles 2000), it may be more so for early career (EC) academics, since there are so many other aspects of their roles that are new and challenging. The focus in this paper is on promoting confidence and productivity in academic writing for EC researchers.

When we started this project, we were EC academics (fewer than five years post $\mathrm{PhD}$ completion) who had been at Keele for between one to four years, in our first full-time lecturing position. Some of us undertook temporary research or teaching contracts following our PhD, which included minimal time dedicated to writing for publication. Since arriving at Keele, the five of us formed a friendship group, which was instrumental in the decision to develop this project.

Individually all the authors had been struggling with our writing and publication activities as part of the transition to a full time academic role. Finding the time, confidence and discipline 
to write had consistently proven elusive. With yet another teaching semester drawing to a close we decided it was time to tackle the problem directly.

\section{Communities of Practice}

We decided to consciously foster a 'community of practice' with the goal of improving our confidence and productivity around academic writing. Wenger-Traynor and Wenger-Traynor (2015 np) describe communities of practice as 'groups of people who share a concern or a passion for something they do and learn how to do it better as they interact regularly'. Outside of formal, acquisitive learning systems, 'people learn through their co-participation in the shared practices of the "community" or the "lived-in world"” (Fuller $2007 \mathrm{np})$. That is, learning occurs through mutual engagement with shared norms, rather than through explicit didactic instruction from 'experts' to 'novices'.

Snyder and Wenger (2010) suggest that a community's effectiveness as a social learning system depends on the specificity of the domain of experience to which members' efforts are focused (in our case academic writing for publication), the strength of the sense of community between the members (how strongly connected the members feel towards each other), and the development and sharing of members' knowledge of practices associated with the relevant domain (discussing and mutually engaging in activities that support the specified domain). Omidvar and Kislov (2014) note that although the theory was originally developed as an analytical perspective on spontaneously occurring communities of practice (Brown and Duguid, 1991; Lave and Wenger, 1991), it has since evolved into a more instrumentalist perspective in which the theory is applied to deliberately cultivate tacit knowledge and shared practice within organisations (Wenger et al., 2002; Wenger and Snyder, 2000). We are seeking to apply the 
principles of a community of practice as a tool to increase our expertise as academic writing practitioners. Thus, our project aligns with more instrumental uses of the theory.

\section{Collaborative Writing}

We draw support for our use of communities of practice in an academic writing context from prior research on the general benefits of collaborative writing. Moore $(2003,334)$ notes that when writing as part of a community, people 'are more likely to learn faster about the conventions and challenges of writing, to support each other at times of blockage and to demystify the process of writing by sharing each other's successes and failures.' One way of creating this community of writers is via co-located writing, such as during a writing retreat.

Moore (2003) evaluated a five-day residential writing 'sanctuary', and reported that participants found the retreat invaluable as they were able to carve out a protected space and focus exclusively on writing for the duration of the retreat. Based on Boice's (1990) analysis of writing-focused 'therapy sessions' with academics, they suggest that structured retreats can improve scholarly output by: providing momentum for writing projects, counteracting selfcensorship, building confidence, providing external motivation, challenging reasons for not writing and by developing writing-related skills. McGrail, Rickard, and Jones' (2006) systematic review of writing interventions found that they did increase publication rates, but perhaps more importantly, led to psychosocial benefits. These included: overcoming writer's block; creating an environment that is non-threatening, inclusive and encouraging; providing participants with the opportunity to exchange ideas without fear of derision; and helping group members be more selfcritical and accepting of feedback. Overall, structured interventions appear to be more effective in developing academic writing than attending didactic writing courses or coaching/mentoring (McGrail et al. 2006; Morss and Murray 2001). 
There is convincing evidence that writing retreats can lead to positive outcomes. However, studies have mainly explored the impact of writing retreats on groups comprised of individuals from a range of writing experiences, abilities, and career stages (Dwyer et al. 2015; Grant 2006; Grzybowski et al. 2003; Murray and Newton 2009), or have focused on experienced regular writers (Moore 2003), or clinicians (Grzybowski et al. 2003). A focus on an EC cohort is important because of the unique challenges they face in adapting to a position where research and scholarship is only one aspect of a new and demanding role. In fact, Moore (2003) explicitly caveats her analysis by stating that the results of retreats attended by experienced writers cannot be taken unproblematically to reflect the experiences of junior academics or novice writers. To our knowledge, the only paper to focus specifically on EC academics was aimed at educators doing research for the first time and was convened by experienced writers (Lee and Boud 2003). Thus, an evaluation of the impact of self-initiated, structured writing retreat interventions on a peer group of EC academics, is worthwhile.

This project aimed to develop an enduring and effective community of practice amongst EC academics focused on the development of academic writing confidence and productivity. We did this in two phases: Phase 1 (writing retreat) aimed to explore the effectiveness of a writing retreat at providing an initial impetus to create a community of practice. Autoethnographic reflection on our experience aimed to identify the key features of the retreat that were conducive to developing good writing practices (Duncan 2004). Phase 2 (writing days) aimed to apply the insights from Phase 1 to extend the community beyond the small group of authors and embed it within our School. 
In this paper we report the results of both interventions and then reflect on their success at fostering an enduring community of practice. We conclude with a discussion of the key considerations relevant for others who are considering implementing a similar intervention.

\section{Writing Retreat}

Although all of us shared frustrations and anxieties around academic writing, none of us had previously participated in a writing group or retreat. Whilst planning our retreat, we discovered Murray and Newton's (2009) paper on the implementation and evaluation of a series of structured writing retreats. Using their suggested structure as a starting point, we incorporated some changes to better suit our goals as EC academics establishing a community of writing practice.

\section{Method}

Murray and Newton's (2009) retreats began with an introductory session on the first evening, followed by two structured writing days. The introductory session encouraged participants to set both short-term (for the first writing session) and long-term writing goals (for the duration of the retreat). Following this, their two writing days were structured around discrete periods of activity including discussion sessions, (when participants collaboratively set and reviewed writing goals and monitored progress), writing sessions, and scheduled breaks. Participants adopted a 'typing pool' model and wrote together in one room over the duration of the retreat. We followed this basic structure for our retreat.

Murray and Newton (2009) included an 'expert facilitator' in their retreat. In contrast, we took turns to act as 'peer facilitators': alongside our own writing, we each periodically assumed responsibility for cultivating the writing community and explicitly focusing on our practice 
development. Table 1 shows the adapted version of Murray and Newton's (2009) schedule that we followed for our retreat.

With our out-of-office email messages set and laptops packed, we headed off to an idyllic cottage in Wales in May, hoping for a productive few days. We did not restrict what kind of writing project participants could work on beyond a focus on academic writing (e.g., conference abstracts, manuscripts, grant applications) whether a new project or a draft in progress. We prepared for the retreat by re-familiarising ourselves with any substantive reading. 
Table 1: Writing Retreat Structure (adapted from Murray and Newton 2009)

\begin{tabular}{|c|c|c|}
\hline Day & Time & Activity \\
\hline \multirow{4}{*}{$\begin{array}{l}\text { Arrival } \\
\text { day }\end{array}$} & $16.15-16.30$ & Welcome, housekeeping etc. \\
\hline & $16.30-17.40$ & $\begin{array}{l}\text { Individually preparing our projects for the writing retreat (gathering } \\
\text { key documents etc) }\end{array}$ \\
\hline & $17.40-17.45$ & Five mins individual free writing exercises \\
\hline & $17.50-18.40$ & Setting individual writing goals: long-, medium-term, and sub goals \\
\hline \multirow[t]{13}{*}{ Day 1} & $09.15-9.30$ & $\begin{array}{l}\text { Group discussion of individual writing goals for first session; warm- } \\
\text { up activity }\end{array}$ \\
\hline & $09.30-11.00$ & Writing Session 1 \\
\hline & $11.00-11.20$ & Break \\
\hline & $11.20-11.30$ & Group discussion: setting/resetting individual writing goals \\
\hline & $11.30-12.30$ & Writing Session 2 \\
\hline & $12.30-13.15$ & Lunch \\
\hline & $13.15-13.30$ & Group discussion: setting/resetting individual writing goals \\
\hline & $13.30-15.00$ & Writing Session 3 \\
\hline & $15.00-15.20$ & Break \\
\hline & $15.20-15.30$ & Group discussion: setting/resetting individual writing goals \\
\hline & $15.30-17.30$ & Writing Session 4 \\
\hline & $17.30-18.00$ & $\begin{array}{l}\text { Group discussion: reviewing individual writing goals, setting new } \\
\text { individual goals }\end{array}$ \\
\hline & Evening & Pub, Monopoly and wine \\
\hline \multirow[t]{12}{*}{ Day 2} & $09.15-09.30$ & Group discussion of individual writing goals for first session \\
\hline & $90.30-11.00$ & Writing session 5 \\
\hline & $11.00-11.20$ & Break \\
\hline & $11.20-11.30$ & Group discussion: setting/resetting individual writing goals \\
\hline & $11.30-12.30$ & Writing session 6 \\
\hline & $12.30-13.15$ & Lunch \\
\hline & $13.15-13.30$ & Group discussion: setting/resetting individual writing goals \\
\hline & $13.30-15.00$ & Writing session 7 \\
\hline & $15.00-15.20$ & Break \\
\hline & $15.20-15.30$ & Group discussion: setting/resetting individual writing goals \\
\hline & $15.30-17.00$ & Writing session 8 \\
\hline & $17.00-18.00$ & $\begin{array}{l}\text { Taking stock: group reflection on achievement of individual retreat } \\
\text { goals }\end{array}$ \\
\hline
\end{tabular}


On the first evening, we discussed the format and guidelines we would use for the retreat. We agreed to reserve chatting and questions for discussions and breaks. The aim was for almost silence during each writing session. We limited our use of the internet during writing sessions to quick reference searches. Emphasis was placed on generating a rapid and expansive word count, rather than crafting a single, perfectly researched and phrased sentence. Finally we agreed to create the atmosphere of supportive surveillance by seeking out ways to draw attention to each other's accomplishments. After establishing the ground rules we worked individually to to prepare ourselves for writing. For most of us this involved re-reading drafts, checking empirical findings, and locating vital references. It served to 'get us in the zone' so that we could maximise the productivity of each writing day.

Like Murray and Newton (2009) we placed particular emphasis on regularly reviewing progress in a supportive fashion. Each individual set their own goal for each writing session and shared it with the group before we began. We then reported our progress towards this goal back to the group after each session. The role of the group was to help the speaker identify their accomplishments, celebrate successes, and suggest strategies for overcoming any barriers to writing in the next session.

In addition to the actual writing interventions, a key feature of this project was the promotion of personal reflexivity around our writing practice. Whereas Murray and Newton (2009) used a neutral interviewer to elicit participants' reflections on their experience, we engaged in a continual process of self-reflection, akin to autoethnographic research. Here, reflection refers to "a process of looking back, as it were, on the ways one's assumptions and actions influence the way one behaves or practices" (du Preez 2008, 510). Wall $(2008,38)$ describes autoethnography as a "giving voice to personal experience for the purpose of extending 
sociological understanding". The utility of this approach lies in the extent to which the written case study, resonates with and informs the practice of others in similar circumstances (Duncan 2004).

We chose this approach because of its practical potential to help with our aim of fostering a community in which we collaboratively share, reflect on and develop our writing practice (Snyder and Wenger, 2010). The process of discussing how different aspects of the interventions affected our writing helped to embed those practices in the shared tacit knowledge of group members. It also facilitated our evaluation of how the community should continue to develop into Phase 2 and beyond. The collaborative nature of our self-reflections also helps to mediate the risk of subjective bias within our evaluation. Ultimately the themes arising from the analysis are the result of group consensus following extensive and on-going discussion.

\section{Results and reflection}

The primary aim of the retreat was to establish a community with positive writing habits, and to improve our confidence and motivation to write. Thus, main analysis of this retreat centres around our ethnographic reflections on qualitative changes in our writing practice. Quantitative outputs, in terms of papers completed or number of words written by the end of the retreat, were gathered in the spirit of acknowledging achievements (not fostering competition) and are reported below only as a crude indication of what we tangibly produced during the retreat.

In total, the five of us wrote a combined 22,535 words during two days of writing. By the end of the retreat four manuscripts were sent to co-authors or colleagues for comment. Perhaps most importantly, we had all thoroughly enjoyed ourselves and felt more positive about our writing practice than any of us could remember feeling before. At the end of the second writing 
day we held an extended discussion and reviewing session to recognise our accomplishments, evaluate our performance and reflect on the process. When reflecting on the retreat we concluded that three main features had contributed to its success: Formal structure, co-location, and peer discussion.

Formal Structure. We found the defined structure to the day useful and productive. The fact that each day was split into subsections helped us to maintain our focus. In general the first sessions of the day were usually the easiest to focus. However, sessions after lunch were more challenging. We addressed this by shortening the after lunch session in subsequent writing days (Phase 2) in order to help us to overcome this sluggish session. Murray and Newton's (2009) retreat only contained three writing sessions on the second day. This had been our intention but we were feeling so positive about the experience that we decided to add in a fourth session to mirror the previous day.

We were strict with our timings and tried to ensure we began and ended our writing promptly. At times we all found it hard to stop writing at the end of a session when things were flowing well. We developed a system of five and one minute warnings to help us to conclude the writing we were doing and make notes for the next session. Just as important as this were the enforced start times where we supported each other in starting challenging sessions. By forcing us to start writing regardless of our own feelings we came to see how much could be achieved even when motivation was relatively low. Sometimes simply starting writing was enough to help us to get 'into the zone'.

As the retreat progressed we worked to achieve a balance of activities that suited us all. For example, originally we did not talk at all during the writing sessions. However, in later sessions we allowed short discussions, for example around word choice. The facilitator 
monitored any exchanges and intervened when they became lengthy or tangential. In this way we maintained a clear distinction between writing and discussion time. This contributed to the sense of bounded periods of intense writing relieved by distinct breaks. It also meant that the discussion time was treated as a valuable and integral part of the activity.

Co-located writing. 'Working alone, the novice writer may experience "writer's block", which produces feelings of anxiety, feelings of being overwhelmed, and worries about rejection' (Grzybowski et al. 2003, 195). All of us reported very clearly that we found being physically around the same table while writing led to greater productivity. Co-located writing did initially make us feel a little self-conscious, but it quickly became the case that whenever our attention wandered and we began to glance around the room, we saw peers working industriously and this helped us to resume concentrated writing quickly.

In addition to the 'typing pool' co-located writing advocated by Murray and Newton (2009), we experimented with selected periods of solitary writing, as was utilised in the retreat reported by Grant and Knowles (2000). Three of us spent time working individually in a separate room but all reported internet-based digression, sofa-based snoozing, or distracted window gazing. We all found that we worked better when we were in the same room so that the example of the majority could encourage each of us in moments of weakness to maintain motivation and prevent us from becoming distracted. Co-location was instrumental in enabling us to stick to the agreed structure of the sessions and benefit from the peer discussions.

Peer discussion. As discussed by Murray and Newton's (2009) participants, regular group reviewing is beneficial as it helps each writer to realise what can and cannot be achieved within a set amount of time. The purpose of this part of the programme was to focus our attention on what was achievable within time-limited writing sessions. This was initially very 
hard to gauge accurately and we were all struck by how unrealistic our estimates were about what could be achieved in a single session. However, we all improved at this over the course of the retreat.

\section{Conclusion}

In line with previously published writing retreats and communities of practice theory, we all found the retreat to be a highly productive endeavour, in terms of output metrics and our renewed vigour and resilience for academic writing. Upon our return from the retreat, we were keen to maintain the momentum we had established, and to share our positive experiences with other colleagues, at different career stages. Thus, in the next phase of our academic writing journey, we adapted our retreat structure to fit within a single day event, which could be repeated at regular intervals in our School.

\section{Writing Days}

The aim of the writing days was to find a way to bring the successful elements of the retreat into our normal working practice and integrate it within the wider research community in the School. These days would hopefully establish an inclusive community of practice, in which all academic members of the department could collectively nurture good writing habits. However, we had really enjoyed the synergy and camaraderie that had developed in our fledgling community of practice during the retreat and were unwilling to completely abandon our successful micro-group. Thus, we arranged four dates over the summer for the Closed group to meet (the five authors of this paper) and three dates that were Open to all psychology staff and postgraduate research students.

\section{Method}


Each writing day followed the schedule outlined in Figure 1. We booked a room in an isolated part of campus to provide the separate mental and physical space we had enjoyed on our retreat whilst not having to spend time and money travelling to an external location.

09.00 - 09.15 - Welcome and goal-setting

$09.15-10.30$ - Session 1

10.30 - 10.50 - Break

10.50 - 11.05 - Progress reviewing and goal-setting

$11.05-12.30$ - Session 2

12.30 - 13.15 - Lunch

13.15 - 13.30 - Progress reviewing and goal-setting

13.30 - 15.00 - Session 3

15.00 - 15.20 - Break

15.20 - 15.40 - Progress reviewing and goal-setting

15.40 - 17.00 - Session 4

17.00 - 17.30 - Discussion and review

17.30 - Pub!

Figure 1: Writing Day Structure

Based on our experience during the writing retreat we revised the schedule and

formalised the 'rules' (Figure 2). We shortened session 3 (after lunch) to minimise the impact of the 'post-lunch slump'. Prior to attending, each confirmed participant emailed the facilitator a description of their goals for the day. This was in lieu of the evening session we had held at the start of the retreat. Our 'rules' were designed to try and recreate the atmosphere of positive encouragement we had found so valuable during our retreat.

1. Writing sessions are for writing

a. Save your questions and reactions for the breaks and discussion sessions

b. Keep reading to the very minimum necessary for writing

2. Discussion sessions should be supportive and safe spaces for discussions

a. Help others recognise their achievements and support them to set realistic goals for the next session

b. Reflect on what worked and what didn't

3. Take breaks - Clear your head, stretch, move around and refresh yourself 


\section{Results and reflection}

Table 2 outlines how many participants attended each of the writing days and what quantitative outputs were achieved. In addition to the five co-authors of this paper, six other participants attended one or more writing days. Although number of words written was recorded for all of the participants at all writing days, information on the number of drafts and outputs is only known for the five authors of this paper and not the other participants. Outputs counted in the table include manuscripts for submission to academic journals, conference abstracts, ethics applications, grant applications, and coursework for postgraduate certificates in teaching and learning in higher education. In total, 63,687 words were produced across the writing days.

Table 2: Writing Day Outputs

\begin{tabular}{lllll}
\hline Type of day & $\begin{array}{l}\text { Number of } \\
\text { participants }\end{array}$ & $\begin{array}{l}\text { Number of } \\
\text { words written }\end{array}$ & $\begin{array}{l}\text { Drafts sent to } \\
\text { co-authors }\end{array}$ & $\begin{array}{l}\text { Outputs } \\
\text { submitted }\end{array}$ \\
\hline Closed Day 1 & 4 & 4,498 & 1 & 4 \\
Closed Day 2 & 5 & 10,673 & 1 & 3 \\
Closed Day 3 & 3 & 6,221 & 1 & 0 \\
Closed Day 4 & 4 & 5,589 & 1 & 0 \\
Open Day 1 & 6 & 10,750 & 0 & 0 \\
Open Day 2 & 6 & 17,500 & 1 & 1 \\
Open Day 3 & $8 \dagger$ & 10,412 & 2 & 7 \\
TOTAL for Closed Writing Days & NA & 26,981 & 4 & 1 \\
TOTAL for Open Writing Days & NA & 38,662 & 3 & 8 \\
TOTAL for all Writing Days & NA & 63,687 & 7 & 0 \\
\hline
\end{tabular}

${ }^{\dagger}$ One person attended for only half the day 
As a quantitative measure, the word counts do provide a tangible indication of productivity. However, this total comes with some caveats - on many days some participants were editing papers rather than starting a new paper from scratch so words were often being removed to make writing more concise. Thus the true number of words produced is likely to be substantially higher than reported in Table 2.

When reflecting on the writing days, both the Closed and the Open days were judged to be highly successful. Attendees reported thoroughly enjoying the day, valuing both the highly structured nature of the schedule and having permission to focus exclusively on their research for a day without worrying about administrative intrusions. We felt that one of the most important 'outputs' that we are not able to quantify is how beneficial the writing process was to our development as writers - sometimes the days we found most productive were not necessarily those that produced the most words but where we had become 'un-stuck' with a problematic passage or had made a dent into a difficult writing task that we had been avoiding.

There are two main points that emerged following our participation and reflection on the writing days that we wish briefly to consider here: career stage and gender.

Career stage. Unexpectedly, the Closed days were quantitatively more productive per participant than the Open days (on average 945 words more per participant). We also noticed a qualitative difference in the atmosphere of the Open sessions, compared to the Closed group sessions, and we put this down to changes in the dynamics of our interactions reflecting different levels in the academic hierarchy. As EC academics, setting goals and subsequently reviewing the extent to which we had met them was more daunting in front of senior colleagues, in spite of their clear support and encouragement. Writing with others who were of a similar career stage seems to have allowed us to be more honest in reflecting on the strengths and weaknesses of our 
own writing. We also felt that when we were discussing issues around confidence in writing we were able to do this more effectively with other EC academics.

The tendency to settle into one's place in the hierarchy was perhaps not just felt by the EC academics. We noted that some senior colleagues tended towards taking on a mentoring role within the discussion sessions, particularly in paired discussions, devoting their time to evaluating their junior colleague's productivity at the expense of sharing their own. We are not trying to imply that mentoring and guidance from senior colleagues is not valuable or useful for EC academics. We are merely suggesting that writing sessions might not be the most effective environment for such activities. Instead, in line with a community of practice approach to learning, a more peer-oriented style of support might facilitate greater productivity. Indeed, the only other paper to have evaluated the efficacy of EC academics' writing groups also concluded that genuine reciprocity, irrespective of hierarchy outside of the writing group, was crucial (Lee and Boud 2003).

We have no data from which to evaluate the impact on more senior colleagues' productivity of the presence of junior colleagues when writing. Therefore we cannot comment on whether they might also be more productive when writing in the company of people at a similar career stage compared to either alone or with more junior colleagues. However, we did observe that several senior colleagues who declined the invitation to participate in the Open writing days commented that, whilst they admired the initiative and wished to support us, they already had established effective independent writing patterns that fitted around their family or personal commitments. In effect, they considered the disruption to their routine that would be required to attend the writing day would be detrimental to their writing productivity. In contrast, the EC 
academics felt the imposition of an external structure could facilitate and enhance their writing practice.

Gender. The writing retreat and the Closed writing days developed from a friendship group of EC academics within our department. It just so happened that we were all female. It is important to acknowledge that for our School it is hard to disentangle EC from gender effects; of the eight junior appointments in recent years, seven have been female. However, we were surprised about the gender distribution in the Open writing days, to which the whole School was invited. Despite there being a roughly even gender split in our School, none of our male colleagues participated while several senior female colleagues did. Instead, two male colleagues who are experienced, innovative, and prolific academic writers offered to run a question and answer / advice session with the Open day attendees about academic writing.

This appears to suggest that, within our School at least, female academics are more likely to seek out support to boost the productivity of their academic writing. We cannot reliably speculate on the reason behind this observation. Further research could explore suggestions raised during the reflection process about whether female academics might disproportionately lack confidence in their writing ability compared to male colleagues, or whether male academics might feel less able to admit a need for support compared to female colleagues. We do know however, that female academics may face a larger struggle to find the place and time to write (Grant 2006), as they frequently balance more time-intensive student-centred teaching practice with wider domestic responsibilities (Beddoes and Pawley 2014; Eagan and Garvey 2015). Colocated structured writing sessions might be a strategy worth considering as a way of supporting female academics, particularly given growing recognition of the need to support women to close the career gap in academia (ECU's Athena SWAN Charter 2016; Howe-Walsh et al. 2016). 


\section{Enduring Community of Practice}

Murray (2015) reflects that while the majority of participants find writing retreats enjoyable and productive, there is inevitably a 'return to reality' and it is then important to maintain motivation and to keep writing. A criticism of extended periods of writing or longer writing retreats is that academics may come to rely or depend upon the ability to block out longer periods of time in order to write successfully (Moore 2003). This was something we were keen to avoid.

We transitioned back from our writing retreat into single writing days over the summer. Our focus then shifted to how to develop the model to protect our writing time and sustain our community of practice around other responsibilities. We started a series of writing mornings for EC academics during term time, which newly recruited colleagues have joined. We have also held several co-located structured writing days either as pairs or small groups depending on people's availability and the projects they are working on.

The results of these changes can been seen tangibly through a comparison of our writing productivity. Between the five authors, in the year before the retreat we submitted five manuscripts for publication, while in the year since the last formal writing day we submitted eleven manuscripts. We take this as good evidence that a) the interventions improved our confidence and productivity at academic writing and b) we have effectively nurtured an enduring community of practice.

Reflecting on the changes to our writing practice, we all now report feeling more able to set and review realistic goals and are better at motivating ourselves to tackle difficult writing tasks. Initially it was easier to see how to improve others' goal-setting than our own. The discussion sessions enabled us to gently interrogate the achievability of each other's goals. We 
all felt that regularly noting and sharing our progress helped us to reflect on how much we had achieved, and create a supportive collegiate atmosphere. By the end of the summer we had learnt how to set achievable goals that would give us a sense of accomplishment. Often this involved recognising when a goal needed to change and how to change it to make it achievable. By increasing the time we spent pursuing a clear goal, we decreased the time we spent procrastinating with smaller peripheral tasks and avoiding the difficult sections of the writing. This specific improvement in one aspect of our writing practice is evidence of the power that can be leveraged through fostering a shared community in which members mutually engage in, and reflect on, their practices related to a specific domain of their lives (Snyder and Wenger 2010).

\section{Discussion}

Although the original idea for our retreat was borne out of our apprehension around the process of writing for publication and concern about our lack of writing output, the concept has developed into something far more transformative for our work practice. Our interventions using co-located writing, structured periods of intense work and supportive peer discussions have changed the way we all approach our writing. Fundamentally we have observed that co-located structured writing is effective. Time-limited periods of intensive work focused our productivity and left us all astounded by how much it was actually possible to write in a short period of time. In addition, we now recognise the value borne by a being part of a truly supportive academic peer group. We have all subsequently been more conscious of the need to nurture this peer group.

\section{Co-located, structured writing, and discussion groups}

We weren't just sitting together and writing. Each session had timed periods of writing, reviewing and resting. Having designated time for writing meant that we were able to focus fully 
on our writing to the exclusion of other tasks. Previously, we had all found it difficult to make time for writing. Papers do not knock on the door or have strict deadlines, so teaching and administrative duties can often take priority if one is not careful to protect writing time. By reclassifying our writing time as a scheduled group meeting, it gained legitimacy in our calendars and become a protected activity.

The discussion sessions were often more powerful in terms of improving our approach to writing than the writing time itself. We were all familiar with the experience of hearing negative reviewer comments in our heads whilst writing. These imagined reviewer comments often led us to be very critical of our papers and, at times, paralysed our writing. The emphasis on recognising others' achievements helped us to begin to replace negative ruminations with positive feedback from peers. This boosted morale and made the process of writing more enjoyable by reducing the anxiety associated with anticipated future external review (Ely, Vinz, Dowling, and Anzul 1997).

The co-located and structured elements of our programme can be achieved in 'Shut up and Write' style sessions (e.g., Mewburn 2013), and discussion groups (e.g., Grzybowski et al. 2003) can support writers to review progress, set goals and share experiences. However, we have found that Murray and Newton's (2009) retreat structure, which we adapted into a flexible programme for co-located, structured, peer-based writing sessions, maximised the benefits provided by the different elements.

\section{Writing Peer Groups}

Whilst all attendees at the writing retreats and days found them a valuable and productive experience, we found that these sessions were more effective when all the attendees were at a similar career stage. This helped to ensure that we were all equal when providing feedback and 
discussing issues and allowed us to be most open and honest about our struggles. When developing a writing group, it may be worth colleagues considering working with others at a similar point in their career, or explicitly directing all attendees to leave the institutional hierarchy at the door and engage in genuinely reciprocal discussions (Lee and Boud 2003).

Where workloads and administrative responsibilities are inhibiting individuals from setting up groups, it might be useful for line managers to be aware that providing academics with dedicated writing time in the company of their peers can help mitigate the challenges faced by competing demands on an academic's time. However, based on our analysis we would concur with Snyder and Wenger (2010) that managers and senior colleagues might be most effectively positioned as external sponsors of knowledge that has been generated endogenously by members, rather than operating as sources of knowledge within a writing community.

Although our Open writing days were productive and enjoyable, there may be a particular benefit for EC academics in creating their own writing community. We feel the success of our initiative lay in the degree to which it created a community of practice in which new academics could legitimately develop their craft skills in a supportive environment free from the pressures and judgements of academic writing. By talking about writing, writing together, and making our tacit learning explicit through reflection we created an effective and valuable community of practice that has in turn nurtured and stimulated our writing potential.

\section{Conclusion}

In summary, we found that peer-led writing workshops led to high levels of productivity. The initial residential retreat helped us to refocus on our writing and to begin to develop a community of practice. The follow-up writing days helped us to maintain this focus on writing and to support each other to grow and develop as writers. To continue our progress, we have 
developed a number of techniques to keep us motivated to write and to maintain our productivity. We see structured writing retreats as a solution to the problems with academic writing and therefore we recommend that colleagues who are experiencing similar issues consider peer-led writing days and get writing!

Acknowledgements: Alexandra Kent is first author of this paper as she initiated the writing group and took the lead writing this paper. All other authors participated equally in writing the manuscript and are ordered alphabetically. We are grateful to the reviewers for their helpful suggestions. 


\section{References}

Beddoes, K. and Pawley, A.L. (2014). 'Different people have different priorities': work-family balance, gender, and the discourse of choice. Studies in Higher Education, 39, 15731585.

Boice, R. 1990. Professors as Writers: a self-help guide to productive writing. Stillwater, OK: New Forums Press.

Brown, J.S. and Duguid, P. (1991). Organizational learning and communities-of-practice: Toward a unified view of working, learning, and innovation. Organization Science, 2, 4057.

Duncan, M. 2004. Autoethnography: Critical appreciation of an emerging art. International Journal of Qualitative Methods, 3(4), 28-39.

Dwyer, T., Friel, D., McAllister, M., Reid Searl, K., and Rossi, J. 2015. The write stuff: A proactive approach to increasing academics' writing skills and outcomes. Nurse Education in Practice, 15, 321-326.

du Preez, J. 2008. Locating the researcher in the research: personal narrative and reflective practice. Reflective Practice, 9, 509-519.

Eagan Jr, M. K., and Garvey, J.C. 2015. Stressing Out: Connecting Race, Gender, and Stress with Faculty Productivity. The Journal of Higher Education, 86, 923-954.

Ely, M., Vinz, R., Dowling, M., and Anzul, M. 1997. On writing qualitative research: Living by Words. London: Falmer Press.

ECU (Equality Challenge Unit) Athena SWAN Charter. 2016. Accessed on 1st October 2016. http://www.ecu.ac.uk/equality-charters/athena-swan/ 
Fuller, A. 2007. Critiquing theories of learning and communities of practice, in J. Hughes, H. Jewson and L. Unwin. (Eds), Communities of Practice: Critical Perspectives, Oxon: Routledge.

Grant, B. M. 2006. Writing in the company of other women: exceeding the boundaries. Studies in Higher Education, 31(4), 483-495.

Grant, B., and Knowles, S. 2000. Flights of imagination: Academic women be(com)ing writers, International Journal for Academic Development, 5(1), 6-19.

Grzybowski, S. C., Bates, J., Calam, B., Alred, J., Martin, R. E., Andrew, R., et al. 2003. A physician peer support writing group. Family Medicine, 35(3), 195-201.

Howe-Walsh, L., Turnbull, S., Papavasileiou, E., and Bozionelos, N. 2016. The Influence of Motherhood on STEM Women Academics' Perceptions of Organizational Support, Mentoring and Networking. Advancing Women in Leadership, 36, 54-63.

Lave, J., and Wenger, E. 1991. Situated Learning: Legitimate Peripheral Participation. Cambridge: Cambridge University Press.

Lee, A. and Boud, D. 2003. Writing groups, change and academic identity: research development as local practice. Studies in Higher Education, 28, 187-200.

McGrail, M. R., Rickard, C. M., and Jones, R., 2006. Publish or perish: a systematic review of interventions to increase academic publication rates. Higher Education Research and Development, 25(1), 19-35.

Mayrath, M. C. 2008. Attributions of productive authors in educational psychology journals. Educational Psychology Review, 20(1), 41-56.

Mewburn, I. 2013. Shut up and Write!, The Thesis Whisper, http://thesiswhisperer.com/shut-upand-write/ Accessed 14th March 2016. 
Moore, S. 2003. Writers' retreats for academics: exploring and increasing the motivation to write, Journal of Further and Higher Education, 27(3), 333-342.

Morss, K., and Murray, R. 2001. Researching academic writing within a structured programme: Insights and outcomes. Studies in Higher Education, 26(1), 35-42.

Murray, R. 2015. Writing in Social Spaces: A Social Processes Approach to Academic Writing. London: Routledge.

Murray, R., and Newton, M. 2009. Writing retreat as structured intervention: margin or mainstream? Higher Education Research \& Development, 28(5), 541-553.

Omidvar, O. and Kislov, R. 2014. The evolution of the communities of practice approach: Toward knowledgeability in a landscape of practice - An interview with Etienne WengerTrayner. Journal of Management Inquiry, 23, 266-275.

Snyder, W. M. and Wenger, E. (2010). Our World as a Learning System: A Communities-ofPractice Approach. In C. Blackmore (Ed) Social Learning Systems and Communities of Practice, Milton Keynes:Springer, 107-124.

Wall, S. 2008. Easier said than done: Writing an autoethnography. International Journal of Qualitative Methods, 7, 38-53.

Wenger, E., McDermott, R., \& Snyder, W. M. 2002. Cultivating communities of practice. Boston, MA: Harvard Business School Press.

Wenger-Traynor, E. and Wenger-Traynor, B. 2015. Introduction to communities of practice: A brief overview of the concept and its uses. Website. Accessed on 25/10/16 from http://wenger-trayner.com/introduction-to-communities-of-practice/ 